\title{
PRACTICAL ASPECTS OF THE USE OF ANTISIPATIVE MANAGEMENT IN THE PROCESS OF ENSURING THE ECONOMIC SECURITY OF AN ENTERPRISE
}

\author{
Andriy SHTANGRET (1) ${ }^{*}$, Elzara TOPALOVA (iD2 2 , Oleg POLOVCEV (iD ${ }^{3}$, \\ Olena CHORNENKA ${ }^{\circledR}$, Andriy MUSIYOVSKYI@5 \\ ${ }^{1,}{ }^{4}$ Faculty of Media Communications and Entrepreneurship, Ukrainian Academy of Printing, Lviv, Ukraine \\ ${ }^{2,3}$ Department of Public Administration and Local Self-Government, \\ Kherson National Technical University, Kherson, Ukraine \\ ${ }^{5}$ Odessa Regional Institute of Public Administration of NAPA under the President of Ukraine, Odessa, Ukraine
}

Received 14 September 2020; accepted 27 May 2021

\begin{abstract}
Operating in an unstable market economy environment, enterprises can achieve success in business, provided that a system of economic security is created, focused on predicting possible changes in the internal and external environment using measures.

As the speed of changes in the external environment increases, it becomes more and more difficult to predict with a sufficient degree of accuracy the nature of changes, which would allow security actors to respond to them in a timely manner and with the most rational use of available resources. Early identification of a possible change in the level of economic security of an enterprise increases the reaction time to it. However, with the increase in the frequency of possible sudden changes, the degree of their predictability decreases. This means that until the moment of obtaining information sufficient for thoughtful measures, there is a shortage of time for their implementation, which can lead to the realisation of a certain threat in the form of losses or lead to the loss of a profitable economic opportunity.

The main purpose of the article is to consider the essence of weak signals, to characterise the process of identifying weak signals, to formulate methodological foundations for the use of antisipative management, to determine the differences between antisipative management and adaptive and anti-crisis management in relation to the process of ensuring the economic security of an enterprise.
\end{abstract}

Keywords: antisipative management, economic security, enterprise, expert survey, decision-making systems, anti-crisis management.

JEL Classification: H12, G32, M10.

\section{Introduction}

The modern environment of the organisation's functioning is characterised by a rapid pace of development and the ultimate level of uncertainty, unpredictability of phenomena, is a consequence of the influence of various factors of the external and internal environment. These factors can cause both a positive and a negative impact on the functioning of the enterprise, therefore, causing the emergence of, respectively and promising opportunities for development or potential threats that impede its successful operation and can cause an intensification of crisis processes with the subsequent termination of economic activity (Menggang, 2013). Such conditions significantly complicate the activities of business entities and require enterprises to maximize their preparation for any unexpected events. Therefore, today a very urgent problem for an organization is the ability to determine in advance all possible changes in the functioning environment at the early stages of occurrence and to provide (predict) the most probable ways of their development, as well as to develop an optimal set of preventive measures that will effectively forestall the onset of potential phenomena (take full advantage of opportunities or prevent the impact of the threat). Today it is important for the development of each business entity to find and introduce into practice new forms and methods of management, the use of which will help stabilize the situation despite the unfavorable

${ }^{*}$ Corresponding author. E-mail: buchk1810@ukr.net

Copyright @ 2021 The Author(s). Published by Vilnius Gediminas Technical University

This is an Open Access article distributed under the terms of the Creative Commons Attribution License (http://creativecommons.org/licenses/by/4.0/), which permits unrestricted use, distribution, and reproduction in any medium, provided the original author and source are credited. 
general economic situation, which in the recent period has been further complicated by the inability of most governments to withstand the COVID-19 pandemic (Hyndman \& Athanasopoulos, 2014).

In rather difficult operating conditions, the effectiveness of traditional management and decision-making systems is critically low. Along with the development of the optimal solution, the importance of adherence to the principle of timeliness increases. That is, a quick and thoroughly prepared response becomes important with the prompt clarification of possible changes that contribute to obtaining new competitive opportunities or increasing the negative impact of certain threats (Adbulaziz, 2016).

The traditional management system focuses on the need to make management decisions due to changes in the main performance indicators and the growth of deviation of the actual performance from the planned. In the face of growing business environment growth rates and increasing uncertainty, such a reaction is mostly belated, and the expected results are characterized by low efficiency. The ability to anticipate possible changes by identifying weak signals that are not pronounced signs of possible changes creates the necessary time reserve for making preventive decisions. It can be argued that the use of management methods based on weak signals not only makes it possible to level, but also to prevent the negative effects of the internal and external environment, that is, to control the level of economic security, thereby creating safe conditions for the development of the enterprise (Khalina et al., 2019).

Antisipative management, which is based on the technology of determining and monitoring changes in the level of weak signals, solves complex problems associated with uncertainty and lack of reliable information about changes in the external and internal environment of enterprises. At the present stage of development, the theoretical foundations of antisipative management are insufficiently covered in the scientific literature, and practical experience of its use at enterprises has not yet accumulated, therefore it is advisable to reveal the essence of antisipative management, highlight its characteristic features and substantiate the role in the process of ensuring the economic security of an enterprise as a necessary condition for maintaining its vitality (Hryhoruk et al., 2019).

The use of weak signals creates real advantages over traditional methods, which ensured the development of antisipative control. The basis for the development of this type of management emerged in the middle of the last century. For example, in the late 1960s, the well-known American automobile concern General Motors did not pay attention to signals that foreshadowed a potential energy crisis. In turn, the Japanese companies, having detected and analyzed this signal, began to produce small cars, saving fuel. It is clear that during the energy crisis, such cars were in great demand among consumers. Whereas, by ignoring the aforementioned signals, General Motors has lost about 30\% of the US market share (Ashley \& Morrison, 1997).
This example clearly shows that in order to effectively use the opportunities of the conditions of the functioning of enterprises, it is advisable to use antisipative management in order to combine information coming from the external environment with the internal actions of the organization. At the same time, failure to foresee change can be a fatal mistake for an enterprise, provoking a deterioration in the market environment with subsequent bankruptcy. With the strengthening of the dynamism of the environment for the operation of the enterprise, in the security subjects, it becomes necessary to begin to take appropriate protective measures even before obtaining complete information (Zhou, 2016). There is a need to track the following important points: first, the appearance of the primary signs of changes in the external and/or internal environment; identifying potential sources of these changes; a general approximate characteristic of the essence of a possible threat, but without specifying the essence of its influence on the level of economic security of an enterprise; determination of measures to counter this threat, although there is still not enough information about it to calculate how it can affect the results of the financial and economic activities of the enterprise; changes in most indicators that show an increase in the level of danger; a decrease in the level of economic security of the enterprise because of the increased influence of the threat. Establishing the first moments of the emergence and development of a threat gives security subjects the necessary reserve of time to develop and implement an optimal solution, but requires the creation of an appropriate information system that would ensure the identification of so-called "weak signals". The advantage of an early response is that it allows you to take timely steps to change the level of economic security of the enterprise, which will happen if security actors wait for the last development of events. It can be argued that the efficiency of the economic security system of an enterprise in conditions of a high level of uncertainty and an increase in the rate of changes in the functioning environment largely depends on the ability to recognize weak signals (Avanesova \& Chuprin, 2017).

Considering the above, the major goal of the article is to study the essence of the phenomenon of weak signals, as well as to form the basis for implementing antisipative management, taking into account the fundamental differences between antisipative and anticrisis management of an enterprise.

\section{Literature review}

Among the limited number of scientific works, antisipative management is considered in many ways. So, Ashley and Morrison (1997) consider this type of management as a tool for finding new opportunities. Harper and Glew (2008), argue that this tool allows you not only to get new opportunities, but also to apply them. A separate group of scientists, including Christek, regards antisipative as a kind of anti-crisis management. Among the famous scientists who have formed the basis for the wider application of 
antisipative management are the English scientists James Morrison and William Ashley. These scientists prove that antisipative management is a systematic process that involves the use of modern methods of collecting information, new models of managerial decision-making, as well as ways to evaluate the results obtained. They emphasize the importance of using this type of control to gain a competitive advantage in a dynamic and highly turbulent environment.

Harper and Glew (2008) and Ganushchak (2017) emphasize that antisipative management is aimed at identifying threats and opportunities in the external environment in order to protect the enterprise from potential hazards or reduce their impact. In addition, the authors argue that antisipative management involves not only identifying opportunities but also the operational ability to take advantage of them in a competitive environment.

The followers of the named scientists can be considered I. Biletskaya, who considers antsipative management as such, in which the company must be able to feel the changes that have not come, but are in the early stages, and M. Dyadyuk, who views it as a powerful means of competition.

Among the limited number of scientific works, antisipative management is considered in many ways. So, Ashley and Morrison (1997) consider this type of management as a tool for finding new opportunities. Harper and Glew (2008) argue that this tool allows you not only to get new opportunities, but also to apply them. A separate group of scientists, including Kristek (1981), regards antisipative as a kind of anti-crisis management. Among the famous scientists who have formed the basis for the wider application of antisipative management are the English scientists Ashley and Morrison (1997). These scientists prove that antisipative management is a systematic process that involves the use of modern methods of collecting information, new models of managerial decision-making, as well as ways to evaluate the results obtained. They emphasize the importance of using this type of control to gain a competitive advantage in a dynamic and highly turbulent environment.

Harper and Glew (2008) emphasize that antisipative management is aimed at identifying threats and opportunities in the external environment in order to protect the enterprise from potential hazards or reduce their impact. In addition, the authors argue that antisipative management involves not only identifying opportunities, but also the operational ability to take advantage of them in a competitive environment.

In addition, such scientists as Dudin et al. (2018) and Ferjencik (2020) have been working on the issues of protecting all the security of components at the enterprise for many years. In turn, Jule (2020) in his scientific works investigated the issue of distinguishing between different types of risks that affect security at the enterprise.

The followers of the named scientists can be considered Biletska (2008), who considers antisipative management as such, in which the company must be able to feel the changes that have not come, but are in the early stages, and Dyadyuk (2015), who views it as a powerful means of competition.

It must be admitted that the majority of scientists interpret antisipative management as anticipatory management based on monitoring the external and internal environment, predicting changes and developing organizational flexibility in the decision-making process. In addition, the prevailing view is that antisipative management is a key basis for achieving long-term organizational success.

It is impossible to reject the existing position, which provides for the consideration of antisipative management as a kind of anti-crisis management. Thus, Kristek (1981) identifies the following types of anti-crisis management: antisipative (advance) management - which is implemented in the event of a potential crisis threat; preventive management - introduced in the presence of symptoms of a latent crisis; reactive management is necessary if the company is in deep crisis.

Despite the versatility and multidirectional views of the authors on the disclosure of the essence of antisipative management, it is also worth investigating the semantics of the term "antisipation" as the basis of this category.

Among the numerous definitions of the term «antisipation» in the reference literature, we have chosen the next one (Adbulaziz, 2016):

- antisipative:

1) an early action that takes into account the provision of an event that will take place later;

2) the use of non-cash money (which are not yet available);

3) visualization of the upcoming event; an object or form that provides for further phenomena;

4) early sounding of one or several tones of the further chord, forming a temporary dissonance.

In accordance with the essence of the definitions presented, antisipation is an action that is aimed at early recognition of a certain phenomenon and prediction of its possible development. It is advisable to consider this as a basic basis for further defining the essence of antisipative management.

Antisipative management has long been the subject of interest of numerous scientists. For example, Glawar (2018), in his work, considered strategies of preventive or, as he called, antisipative management. He proposed to form antisipative management strategies, depending on the current state of the enterprise.

Artun (2015) in his work applied an anti-sipative management system in the field of marketing, allowed him to form optimized systems for dealing with clients, became a powerful basis for maintaining the economic security of an enterprise.

Along with this, it should be noted that in the field of ensuring the economic security of an enterprise of antisipative management, it is considered only fragmentarily as a possible tool for preventing an increase in the level of 
danger. The issue of the essence of weak signals and tracking their changes, which would ensure the formation by security subjects of the necessary information basis for the implementation of the system of protective measures, is poorly researched, which actualizes the need for research in this area.

In the scientific literature, the term "weak signals" is presented with certain differences. We focus on these differences. Kopytko (2014) defines their essence as "the initial signs of future changes in the internal and/or external environment, which show a probable occurrence and sources of negative consequences for the enterprise", we are talking about any changes in the functioning environment that may have negative consequences in the future. Stelmashenko (2018) and Tsmots (2014) point to the need not only to record the presence of such signals but also to track their changes and transform them into strong signals. Pakhomova (2011) proves the need for a timely response to the appearance of weak signals in order to prevent the intensification of crisis processes and bankruptcy of the enterprise.

Some publications attempt to classify weak signals. So, Tsmots (2014) distinguishes economic, socio-cultural, political, production-technological, market, competitive and international groups of the weak. Dyadyuk (2015) argues that it is advisable for enterprises to focus on weak signals from the external environment and identifies a number of such possible signals. Taranenko (2014) divides signals by the spheres of the enterprise's activity, namely production, technological, marketing, logistic, and financial. It should be noted that regarding economic security, an attempt to identify weak signals was made by Kopytko (2014), who singles out the financial, personnel, technical and technological, innovative, production, information, environmental, power, and legal subsystem of signals of the internal environment. Kopytko's (2014) approach can be considered interesting, but the content of the main weak signals requires clarification. For example, in the field of financial security, the author singles out such weak signals as "the use of outdated financial and economic management technologies", "decrease in profitability", etc. In our point of view, most of these signals are characterized by an insufficient level of specification, and it is also expedient to attribute them rather to "strong signals" that show a significant decrease in the level of economic security of the enterprise. Thus, the problems of structuring weak signals require further coordination for the distribution of managerial actions in ensuring the economic security of an enterprise, the definition of principles and approaches to building an information system that could provide information support for security subjects in organizing management based on weak signals.

\section{Research model}

Summarizing, perhaps most scientists interpret the concept of weak signals only from the point of view of management as early signs of an impending crisis. Partly agreeing with this position, we believe that weak signals in the field of ensuring economic security form the necessary information basis for the development and application of measures aimed at stabilizing the situation and creating safe conditions for development. Such signals can be detected because of monitoring changes in certain indicators that characterize the most important parameters of the economic security of an enterprise. Using control based on weak signals today is complicated by the lack of a unified, intelligent and accessible sequence for studying weak signals of the functioning environment, the complexity and laboriousness of using the available methods for completing weak signals from the functioning environment, the complexity of processing weak signals from the functioning environment, the complexity of obtaining information about weak signals. The above points to the consideration of the process of identifying weak signals in the field of ensuring the economic security of the enterprise. Such a process should comprise several interrelated stages (Sylkin et al., 2019).

Achieving this goal requires a systematic approach, within which the following methods will be used: induction and deduction, comparison and systematization - to study the essential characteristics and the evolution of basic concepts; analysis and synthesis - when determining the main parameters of weak signals; questionnaires and expert analysis - to create a system of indicators that ensure the identification of weak signals in the field of ensuring the economic security of the enterprise; modeling to develop a conceptual model for the application of antisipative, adaptive and anti-crisis management in the field of ensuring the economic security of an enterprise; morphological analysis - to clarify the conceptual and categorical apparatus with the problem; graphic - with a visual presentation of theoretical and methodological material; abstract-logical - for theoretical generalizations and conclusions of the study.

In addition, the authors chose the method of expert judgement as the major method. A necessary condition for the effective application of expert assessment methods is sufficient knowledge of the expert on the problem under study, a high level of erudition, his ability to give clear and comprehensive answers, impromptu. In addition, the expert should not be interested in one or another solution to the problem posed to him. Experts are selected on the basis of their formal professional status - position, academic degree, length of service, etc. This selection contributes to the fact that among the experts are highly professional specialists with extensive practical experience in this area.

When applying the method of expert assessments, we conducted a survey of a special group of experts (5 people) in order to determine certain variables necessary to assess the issue under study. All selected experts were experts in economic security and enterprise management. The selection of these experts took place in two stages. The first step was to test professionalism, and the next step was to select those with at least 15 years of experience in this area. 
Each expert was sent a questionnaire with specialized questions. The survey process took place remotely, using e-mails and online calls, taking into account the existing unstable epidemic situation. The questionnaire was created on the basis of information from leading experts in the field of economic security at the enterprise. The structure of the questionnaire provided a sequence of records that related to determining the level of economic security in the enterprise. as well as the success of the use of the models proposed by the authors. The main purpose of using questionnaires is to form a realistic assessment of the effectiveness of the proposed questionnaire authors.

The information base of the study was the reporting and primary documentation of enterprises, the results of a survey of experts among leading specialists of enterprises, scientists and representatives of state authorities, reference and information publications, works of domestic and foreign scientists and practitioners, Internet resources.

\section{Results}

The first stage should provide for obtaining the information about changes in the internal and external environment. Such information should come from all divisions of the enterprise on the primary objects of the "field of observation". In the conditions of each individual enterprise, its own "observation field" is formed, which includes a list of security objects. For example, the external field is associated with the activities of competitors, suppliers, consumers, representatives of the local community, etc. The list of field objects should change based on the experience gained in implementing protective measures in the past. Information should be received systematically and meet established quality criteria.

The second stage is associated with the study of weak signals. It is about tracking their change over time, that is, determining the frequency of appearance and change in strength. An increase in frequency indicates an intensification of a certain phenomenon or process, which in the future can turn into a source of threat. The change in strength provides timelines for the development and implementation of protective measures. Tracking these parameters allows you to cut off the so-called "information noise", which contains random and non-systemic signals that are not directly related to the process of ensuring the economic security of the enterprise.

The third stage is associated with determining the trajectory of transformation of a weak signal into a strong one. The basis for such a definition should be execution indicators characterizing the level of security for each of the functional components of the economic security of the enterprise. The selection of indicators is accompanied by an analysis of their dynamics and determination of deviations, which indicate the strengthening of a weak signal and its transformation into a strong one. To carry out such an analysis, the following are used:

- questioning - a study of the opinion of specialists or target groups in order to confirm or refute the identified tendencies of the environment;
- extrapolation - involves the construction of time series of changes in the value of the phenomenon under study over a certain period of time;

- modeling (using methods of neural networks, control systems, scenarios, imitation, graphs, matrices, selection of indicators, graphical methods, etc.);

- to study changes in the predictive phenomenon with the existing complex of qualitative and quantitative features.

The fourth stage is to identify the reasons for the amplification of the signal and predict the possible consequences.

The fifth stage provides for the development of scenarios for the development of events and the future state of the enterprise with a likely increase in the negative impact of a certain threat.

The sixth stage is to form the necessary information basis for the development and adoption of security management decisions, focused and stabilization of the situation and avoid reducing the level of economic security of the enterprise.

The identified stages are a generalization of already known ideas about the nature of weak signals, which are present in a few scientific publications. We rejected significantly different views on the possible process of detecting such signals and considered the specifics of ensuring the economic security of the enterprise.

Antisipative management in the process of ensuring the economic security of an enterprise can be defined as purposeful activity, provides for the early identification of potential changes in the external and internal environment on the basis of weak signals and the formation on this basis of a multivariate scenario, which reflects the totality of probable ways of development of possible events and a set of alternative protective measures adequate to them, in order to make an optimal management decision aimed at overcoming threats or using new competitive opportunities to continue functioning and achieve strategic goals (Ganushchak, 2017).

Antisipative management is based on potential changes in the functioning environment, those that have not yet occurred, but there is a possibility of their future occurrence and a significant impact on the organization's activities. This approach permeates the entire process of implementing this type of management at the enterprise. According to this position, the use of antisipative management allows to get ahead of the onset and impact of any unpredictable changes in the functioning environment. That is, the enterprise gains the ability to prepare for various potential events by early detection of unexpected events, predicting their most likely development and developing on this basis a set of preventive measures. Thus, antisipative management is an effective way to ensure effective and uninterrupted operation of an enterprise in conditions of high uncertainty in the functioning environment. 
During the economic crisis, the relevance of the use of antisipative management at enterprises is significantly enhanced, since it acts as a powerful way to protect an organization from possible threats. Having foreseen potential threats in time, the enterprise, even before their occurrence and negative impact, already owns prepared measures to counter the increase in the level of danger.

Antisipative management is one of three options for dealing with a threat. In the presence of weak signals, antisipative control is applied. In a situation of transformation of weak signals into strong ones, adaptive management becomes relevant, and in conditions of a significant change in the level of economic security, it is necessary to use anti-crisis management. This approach is graphically presented in Figure 1.

The choice of a certain type of management is based on the determination of the level of a set of indicators in the context of the main functional components of the economic security of an enterprise. The number and content of functional components must correspond to the peculiarities of the financial and economic activities of this enterprise. We offer five such functional components: financial, personnel, technical and technological, information and power. To characterize the safety level for each of the following functional components, based on a survey of experts, a list of indicators has been formed. A change in any of the indicators can be considered a weak signal, and forms the necessary information basis for the use of antisipative control. A change can be considered a deviation in comparison with the standard or the previous value, more than $20 \%$. On the basis of the values of individual indicators, taking into account the share of each of them, which is established by the expert method, the group integral indicators are calculated. A change in any of these group integral indicators (more than 20\%) indicates the transformation of a weak signal into a strong one, which already requires the use of adaptive control. Taking into account the share of each of the functional components in the structure of the economic security of the enterprise, a general integral indicator is calculated. A decrease in this overall indicator (more than 20\%) indicates a decrease in the level of safety, requires the use of anti-crisis management.

The tasks set in the study do not provide for a thorough consideration of the essence of adaptive and anti-crisis management, but we consider it appropriate to stipulate their differences from anti-crisis management. So the purpose of anti-crisis management is to ensure the restoration of the viability of an individual enterprise and prevent the emergence of a situation of its bankruptcy. Adaptive control is focused on an adequate change in the parameters, structure and properties of the control object, when antisipative control is carried out with the aim of making an optimal management decision preceding the negative impact of a particular threat or provides an opportunity to take advantage of advantageous competitive opportunities for functioning.

In order to experimentally test the conceptual model of the implementation of antisipative, adaptive and anticrisis management in the field of ensuring the economic security of an enterprise, we have selected 10 enterprises located in Poland and Ukraine.

To begin with, an integral indicator for each of the types of security was calculated for each enterprise (the value of this indicator ranged from 0 to 1 ).

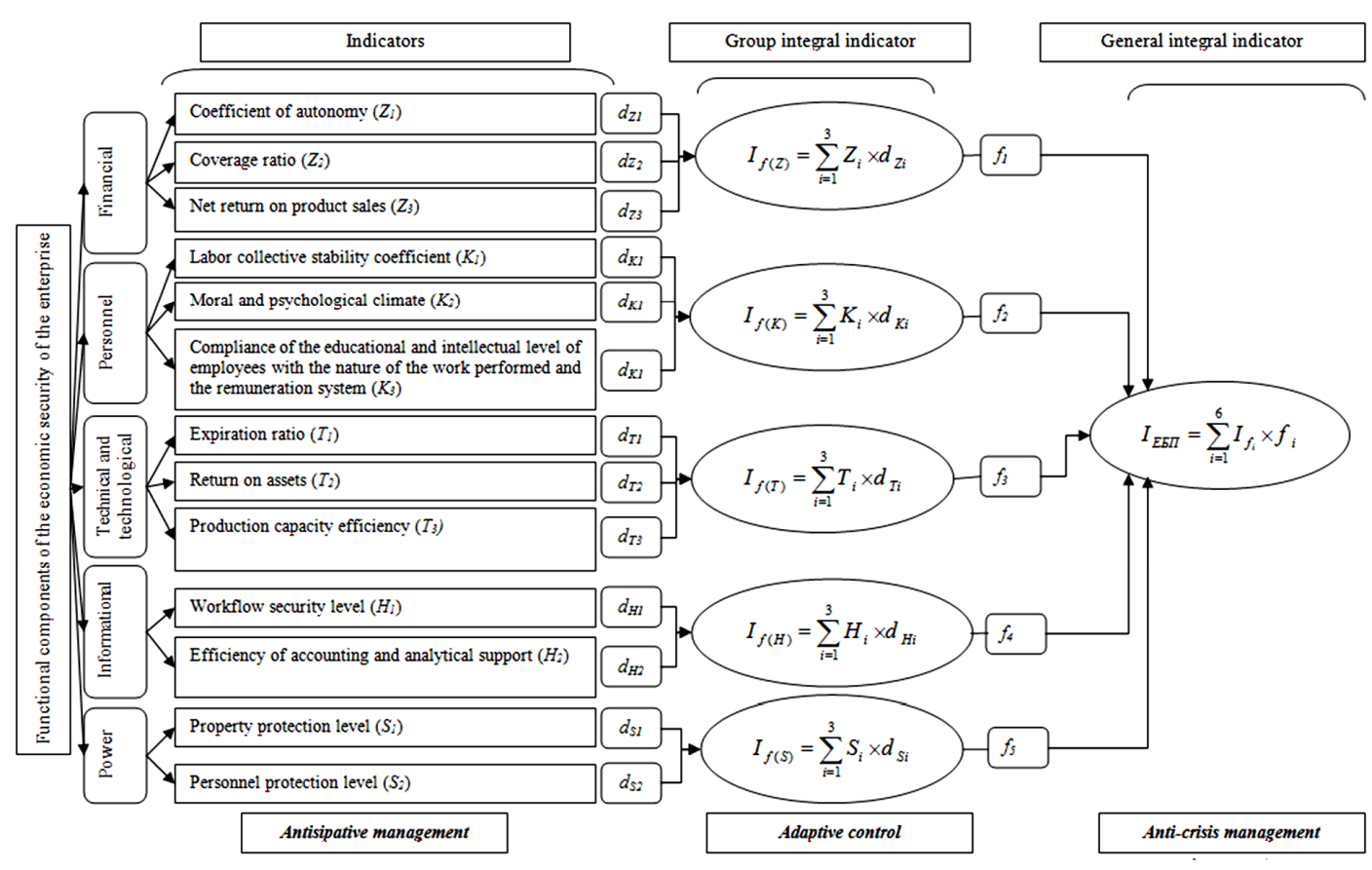

Figure 1. Conceptual model of the application of antisipative, adaptive and anti-crisis management in the field of ensuring the economic security of an enterprise 
According to the presented conceptual model, the next step was to calculate the overall integral indicator, the value of which ranged from 0 to 1 .

According to the results obtained, those enterprises, the value of the overall integral indicator of which is less than 0.5 , have signs of crisis phenomena and are successful in implementing anti-crisis management. In our case, according to Figure 2, these enterprises are enterprises numbered 1, 2, 7, 9 .

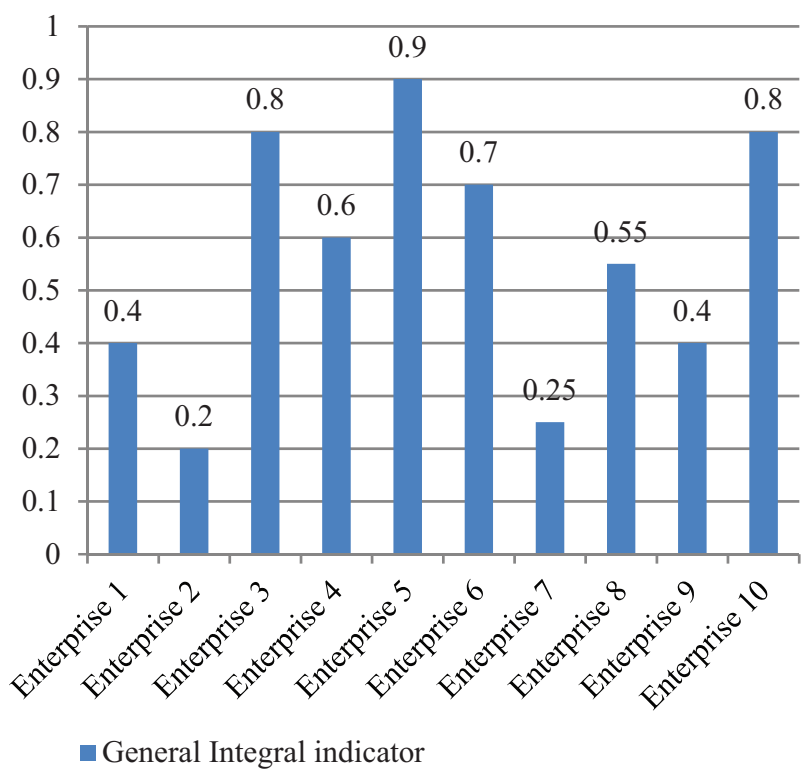

Figure 2. General integrated indicator for selected enterprises of Poland and Ukraine

Anti-crisis management is carried out in pre-, postcrisis and the actual crisis periods. Adaptive management provides for continuous monitoring throughout the entire period of its existence. Antisipative management is a systematic activity that occurs on an ongoing basis, and prevents the manifestation of a crisis at the enterprise, but, on the contrary, is aimed at anticipating its onset.

Anti-crisis management mainly focuses on the rapid identification of signs of a crisis state of the enterprise, using such tools as performance analysis, rapid analysis of financial stability, rating, etc. Adaptive management involves the use of forecasting methods, adjustments, "feedback", planning and response systems, marketing research. In turn, antisipative management is designed to anticipate potential changes in the functioning environment that have not yet occurred, and operates with the main forecasting methods (Sylkin et al., 2018).

Summarizing, it can be argued that security subjects, in order to stabilize the situation and create safe conditions for the development of an enterprise, must use all of the listed and characterized types of management. Antisipative management offers the advantage of slackening time and making better use of available resources.

Considering the significant advantages of using antisipative management, we focus on certain methodological aspects of its application. Thus, the basic goal of antisipative management in the process of ensuring the economic security of an enterprise is to achieve and maintain the highest possible level of preparation of the enterprise for any unexpected events on the basis of developed management decisions to effectively anticipate the emergence and development of internal and external threats. The implementation of specific tasks is determined by the specific features of ensuring security in the context of the main functional components of the economic security of the enterprise, that is, technology, methods, management decisions, and the like. The implementation of each task requires specific skills and abilities of qualified workers for the purposeful collection and processing of information, specialized software and hardware, and the like.

The use of antisipative management is possible due to the observance of the following principles:

- the principle of systematicity, which comprises the constant application of measures to identify and track the transformation of weak signals;

- the principle of complexity, determines the need to track weak signals regarding all functional components of the economic security of an enterprise;

- the principle of adequacy involves the development and adoption of management decisions by security subjects in accordance with the identified weak signals and forecasting the consequences of their impact;

- the principle of priority, which determines the order of ranking the identified opportunities and threats according to the degree of importance and urgency in accordance with the tasks of stabilizing the situation and creating a safe operating environment.

Using antisipative management requires resource provision. First of all, we are talking about staffing, which consists of attracting workers of a sufficient level of qualification with the necessary skills in managerial, mathematical, analytical direction in order to detect and track the dynamics of weak signals. The development of software and hardware greatly simplifies the procedure for identifying, processing and analyzing information signals of potential opportunities and threats, while reducing the workload on employees. In addition, the use of specialized software products (SPSS, Statistica, Forecast Expert, Matlab, Gretl, E-views, etc.) makes it possible to implement a variety of techniques to anticipate the onset of potential phenomena, increasing their effectiveness. Antisipative management cannot be fully automated, since performing individual tasks, including those related to the use of programs, requires the skills and abilities of qualified personnel. The importance of the formation of information support was repeatedly noted, which should form both through information and analytical support of enterprise management and through special research. 


\section{Discussion}

If we compare the study conducted by the authors and a similar study conducted recently, it is worth noting that the study conducted by the authors has a number of advantages and has significant scientific novelty.

For example, Bucher et al. (2020) in their work also used the algorithm for applying antispative control, but, the antisipative control was applied stochastic, without the existence of any aim prerequisites for it. This means that anti-crisis management is used at a stage when there is already a need to use more aggressive anti-crisis management.

Another study that formed the basis for the use of antisipative management was carried out by Krykavskyy et al. (2020), who proposed the use of antisipative management in the marketing of products. In this study, the authors clearly specified the phenomena of signal indicators for the use of antisipative control, and at the same time, in this work, there is practically no mathematical basis for the use of antisipative control. In the authors' study, all steps to introduce antisipative management are supported by mathematical foundations.

As for the study by Bondarenko (2017), who investigated systems for optimizing enterprise strategies in crisis and pre-crisis times, this study also proposed to use antisipative management. At the same time, the author completely neglected the fact that sometimes there is a need to abandon the use of anti-crisis management, and a gradual transition to a more aggressive anti-crisis management. In our work, based on clear mathematical calculations, it is proposed to use one of three types of management: antisipative, adaptive and anti-crisis.

\section{Conclusions}

In the future, it is necessary to put into practice the proposed model assessing the level of economic security of agroindustrial entrepreneurship at individual enterprises in the world.

Using antisipative management in the process of ensuring the economic security of an enterprise contributes to the achievement and maintenance of the required level of preparedness of the organization for any unexpected events of the internal and external environment. The importance of the formation and use of this type of management at the enterprise is intensified in the conditions of hyperdynamic and extreme unpredictability of the functioning environment, because implementing only forecasting as a process within a specific type of management under such circumstances is not enough. This situation requires the enterprise to introduce an antisipative management system based on implementing a complete management process in order to form preventive decisions aimed at effectively expecting changes in the operating conditions.

The basis for identifying weak signals and tracking their transformation in the conditions of a certain enterprise should be a developed conceptual model of the application of antisipative, adaptive and anti-crisis management in the field of ensuring the economic security of an enterprise. The complexity of the application of each of the specific types of management creates conditions for the fulfillment of tasks in the field of ensuring the economic security of an enterprise.

The most significant advantage of antisipative management is the ability to identify signs of changes in the operating environment, when real events that can significantly affect the level of security of the enterprise have a low probability of implementation. The resulting reserve of time contributes to the use of preventive protective measures at a higher level of efficiency of their implementation.

Original value. According to the results of our research, the article can be considered valuable in that it systematizes such a complex process as the use of antisipative control, having formed a model for the application of the latter, it suggests the use of weak signals to optimize antisipative control.

\section{Author contributions}

The authors contributed equally.

\section{Disclosure statement}

The authors do not have any conflict of interest.

\section{References}

Adbulaziz, A. (2016). Formation of the organizational-economic mechanism of anti-crisis management of the enterprise. In Thesis for the degree of candidate of economic sciences. Lugansk National Agrarian University, Kharkov.

Artun, O. (2015). Predictive marketing: easy ways every marketer can use customer analytics and big data. Wiley. https://doi.org/10.1002/9781119175803

Ashley, W., \& Morrison, J. (1997). Anticipatory management: tools for better decision making. The Futurist, 31(5), 47-50.

Avanesova, N., \& Chuprin, Y. (2017). Enterprise economic security: essential characteristics of the concept. Innovative Technologies and Scientific Solutions for Industries, 1(1), 98-102. https://doi.org/10.30837/2522-9818.2017.1.098

Biletska, I. (2008). Features of strategic management when choosing a competitive position of a tourist enterprise. DITB Bulletin, 12, 13-18.

Bucher, E., Schou, P., \& Waldkirch, M. (2020). Pacifying the algorithm - Anticipatory compliance in the face of algorithmic management in the gig economy. Special Issue: Dark Side of Digitalization. Organization, 28(1), 44-67. https://doi.org/10.1177/1350508420961531

Bondarenko, G. T. (2017). Optimization of the company strategic management system in the context of economic instability. European Research Studies Journal, 20(2B), 3-24. https://doi.org/10.35808/ersj/663

Dyadyuk, M. (2015). Management of weak signals in the system of adaptive management of trade enterprises. Economic Strategy and Prospects for Trade and Services, 2, 74-83. 
Dudin, M., Burkaltseva, D., Reznikova, O., Betskov, A., Kilyaskhanov, H., Guk, O., \& Zotova, S. (2018). The impact of conflict on economic security of the enterprise. International Journal of Engineering and Technology (UAE), 7, 283-290. https://doi.org/10.14419/ijet.v7i3.14.16907

Ferjencik, M. (2020). Practical safety management for small or medium enterprises. Journal of Loss Prevention in the Process Industries, 68, 104281. https://doi.org/10.1016/j.jlp.2020.104281

Ganushchak, T. (2017). Dynamics of development of financial safety of the enterprise as a complex economic security of the state. Baltic Journal of Economic Studies, 3(4), 32-36. https://doi.org/10.30525/2256-0742/2017-3-4-32-37

Glawar, R. (2018). An approach for the integration of anticipative maintenance strategies within a production planning and control model. Procedia CIRP, 67(2018), 46-51. https://doi.org/10.1016/j.procir.2017.12.174

Harper, S., \& Glew, D. (2008). Anticipatory management cannot be compromised. Industrial Engineering, 40(8), 34.

Hryhoruk, P., Khrushch, N., \& Grygoruk, S. (2019). Model for assessment of the financial security level of the enterprise based of the desirability scale. In SHS Web Conference, 65. https://doi.org/10.1051/shsconf/20196503005

Hyndman, R. J., \& Athanasopoulos, G. (2014). Forecasting: principles and practice (2nd ed.). OTexts. OTexts.com/fpp2

Jule, J. G. (2020). Workplace safety: a strategy for enterprise risk management. Workplace Health \& Safety, 68(8), 360-365. https://doi.org/10.1177/2165079920916654

Khalina, O., Bazyliuk, V., Chornenka, O., Krasilych, I., \& Korzh, M. (2019). Formation of organizational support for the management of the economic security of engineering enterprises: methodical and practical aspects. Business: Theory and Practice, 20, 317-328. https://doi.org/10.3846/btp.2019.30

Krystek, U. (1981). Krisenbewaltingungs-Management und Unternehmungsplanung. In Neue betriebswirtschaftliche Forschung, Vol. 17. Gabler Verlag.

https://doi.org/10.1007/978-3-322-89289-8
Kopytko, M. (2014). Detection of weak signals of the operating environment as a guarantee of formation of a high level of economic security of industrial enterprises. Economy and State, 11, 24-27.

Krykavskyy, Y., Kuryliak, O., \& Fihun, N. (2020). The features of anticipative marketing in the process of products promotion. ASEJ Scientific Journal of Bielsko-Biala School of Finance and Law, 24, 15-21. https://doi.org/10.5604/01.3001.0014.3307

Menggang, L. (2013). Research on industrial security theory. Springer Heidelberg.

Pakhomova, T. (2011). Anti-crisis management as the most important condition for sustainable development of enterprises. Bulletin, 14, 39-40.

Stelmashenko, O. (2018). Features of strategic enterprise management. http://nauka.kushnir.mk.ua/?p=55777

Sylkin, O., Kryshtanovych, M., Zachepa, A., Bilous, S., \& Krasko, A. (2019). Modeling the process of applying anti-crisis management in the system of ensuring financial security of the enterprise. Business: Theory and Practice, 20, 446-455. https://doi.org/10.3846/btp.2019.41

Sylkin, O., Shtangret, A., Ogirko, O., \& Melnikov, A. (2018). Assessing the financial security of the engineering enterprises as preconditions of application of anti-crisis management: practical aspect. Business and Economic Horizons, 14(4), 926-940. https://doi.org/10.15208/beh.2018.63

Taranenko, S. (2014). The need for enterprise management in weak signals. Bulletin of Khmelnytsky National University, 2, 225-228.

Tsmots, A. (2014). Adaptive enterprise management based on weak signals. Actual Problems of the Economy, 11, 462-468.

Zhou, B. (2016). Enterprises treasury management strategy in post financial crisis era. Quality Technology and Quantitative Management, 11(2), 217-222. https://doi.org/10.1080/16843703.2014.11673338 